\title{
NUTRITIONAL IMBALANCE AND PHYSICAL ACTIVITY, A COMPARISON AMONG STUDENTS BELONGING TO DIFFERENT SOCIOECONOMIC STATUS IN METROPOLITAN CITY OF PAKISTAN
}

\author{
Toqeer Ahmed Iqbal', Zafar Hayat Maiken², Sana Ghaffar Bajwa ${ }^{3}$, Sidra Naseem Malik ${ }^{3}$, Wara Qazi ${ }^{3}$
}

${ }^{1}$ Assistant Professor of Anatomy, Federal Medical \& Dental College, Shaheed Zulfiqar Ali Bhutto Medical University, Islamabad

${ }^{2}$ Associate Professor of Community Medicine, Federal Medical \& Dental College, Shaheed Zulfiqar Ali Bhutto Medical University, Islamabad

${ }^{3}$ Department of Public Health, Federal Medical \& Dental College, Shaheed Zulfiqar Ali Bhutto Medical University, Islamabad.

Correspondence: Zafar Hayat Maiken. Email: drzafarmaken@gmail.com

\begin{abstract}
Background: Balanced diet and optimal physical activity are necessary to maintain health and prevent diseases. Physical and mental growth of children is affected adversely by nutritional imbalance and lack of physical activity. The main factors which are responsible for nutritional imbalance are inadequate food intake and poor health status due to poverty, lack of access to food and family size. Physical inactivity is a major risk factor for cardiovascular disease, cancer, diabetes, and chronic respiratory disease. Children and adolescents are at higher risk to nutritional imbalance.

Methods: In this descriptive cross sectional study, a structured questionnaire was filled by 332 students of different age groups (11_16 years) in different public and private schools of Islamabad and Rawalpindi for 3 months. Sampling technique was simple random sampling.

Results: The data obtained was analyzed using SPSS software. Out of 332 respondents 111 (33.3\%) belonged to low socioeconomic class, $111(33.3 \%)$ of middle class and $110(33.2 \%)$ of high class. The age of respondents was found similar in the three SES categories ( $p$-value $=0.10)$ While calculating the BMI in three socio-economic classes (SES), we found that incidence of underweight (BMI <18.5) was higher in respondents from low SES while that of preobesity (BMI 25_29) was higher in high SES. No significant difference was found in normal and obese respondents among different SES. The incidence of adequate physical activity was slightly higher in respondents of low SES.
\end{abstract}

Conclusion: the incidence of nutritional imbalance and physical activity is significantly different in population of different socioeconomic status

Keywords: Nutrition, physical activity, socioeconomic status, obesity

\section{Introduction}

The recent shifts in environment regarding lifestyle and nutrition have had immense impact on the health status of young children. On one hand, there have been few opportunities for physical activity while on the other, an abundance of high calorie foods (1). Diet is an essential component influencing children's growth and development. A diet deficient in essential nutrients can result in impaired immune system, increased susceptibility to diseases, and slowed physical and mental development (2). No single food will provide us with the right amount of nutrients. By combining foods from all the different food groups, we can meet our body's daily needs. Nutritional imbalance is a disorder caused by either a deficiency or an excess of certain nutrients such as carbohydrates, proteins, fats, vitamins or minerals; it may also result from malabsorption of these nutrients in the body (3).

Physical activity is defined as any body movement generated by skeletal muscles, which involves energy expenditure more than resting e.g. walking, running, cycling, gardening or participating in sports. Although exercise is a form of physical activity that is carefully designed and organized, it usually pertains to movement that enhances health status of an individual (4). A healthy diet and optimum physical activity can help protect against overweight and obesity as well as some of the non-communicable diseases (NCDs) including heart disease, stroke, osteoporosis and cancer, which have increased in prevalence over the years (5). Many forms of physical activity enable young people to connect with their peers and develop important social 
skills (6). It is natural that food habits developed during childhood generally persist into adult life (7).

Total family income along with family size plays a crucial role in the development of food preferences and food intake of children, which may have an impact on their weights in the long-term (8). It can often have profound effects on a person's health. An adequate food intake is one of the major human requirements but there is no one denying the fact that millions of people are beset with danger because of nutritional imbalance (9).

The food quality, selection of food and one's preference for a particular food, whether healthy or not, connects socioeconomic status to dietary practice among individuals (10). Socioeconomic status (SES) is determined via combination of factors including income of individual, level of education, and occupation, which tells how individuals or families fit into society using economic and social measures that have been shown to impact individuals' health and well-being (11).

According to National Nutrition Survey (NNS) 2011, $31.5 \%$ children were undernourished, $15.1 \%$ were wasted and $43.7 \%$ were stunted. Just three countries account for half of malnourished children globally and Pakistan is one of them (12). The most recent estimates by the United Nations Food and Agriculture Organization (FAO) states that 37.5 million people in Pakistan are not receiving proper nourishment. Only $3 \%$ of children receive a diet that meets the minimum standards of dietary diversity (13).

Peter Jaret in 7 Signs of Inadequate Nutrition mentions that nutritional imbalance and reduced physical activity together have symptoms such as weight gain or loss, unexplained fatigue, mood swings, irritability, impaired cognitive development, muscle and joint pain, difficulty in night vision, metabolic disorders, weakened immune system and cardiovascular health issues (14).

Pakistan ranked sixth most populated country of the world (15). The level of socioeconomic development is still low and one fourth of the total population lives below poverty line (16).

However not a single interventional study has been done so far and also literature is not supported regarding the practices of students and parents who are responsible for maintenance of balanced diet and optimum physical activity. Hence, this study has focused on healthy dietary practices and physical activity of school going children.

\section{Methodology}

It is a descriptive and quantitative research in which a cross sectional survey held among different schools of Islamabad and Rawalpindi. A structured questionnaire with a demographic sheet including age, education, weight and height was constructed to assess relationship between nutrition and physical activity, and their combined effect on body health and lifestyle of students of different socioeconomic status. The questionnaire was inspected for data quality and completeness of information. Sample size has been calculated using WHO sample size calculator according to following statistical assumptions; Confidence level= $95 \%$, Alpha error $=5 \%$, Anticipated population proportion $=31.5 \%$. Therefore, study sample size was 332 cases. Simple random sampling technique was used. Data was collected from students of different private and public sector schools of Islamabad and Rawalpindi in duration of 3 months. Data was analyzed using SPSS software version 20.0. Descriptive statistics were applied to measure frequency and percentages in the proportions of SES categories. Chi square test was used to compare the proportions of different categorical study parameters with SES categories. The continuous parameters were compared using ANOVA test. A significance level of $<0.05$ was set. The results were presented in tables, graphs and charts.

\section{Results}

In this study, 332 respondents from seven schools of Islamabad/ Rawalpindi belonging to different SES and gender were included. The distribution of gender according to SES was significantly different $(p$-value = $<0.001$ ). (Table 1).

Table 1: Socio-demographic characteristics of respondents according to SES groups

\begin{tabular}{|c|c|c|c|c|c|}
\hline \multicolumn{2}{|c|}{ Variables } & \multirow{2}{*}{$\begin{array}{l}\text { Low } \\
(\mathbf{n}=111) \\
32(28.8 \%)\end{array}$} & \multirow{2}{*}{\begin{tabular}{|l}
$\begin{array}{l}\text { Middle } \\
(\mathbf{n}=\mathbf{1 1 1})\end{array}$ \\
$43(38.7 \%)$
\end{tabular}} & \multirow{2}{*}{$\begin{array}{l}\begin{array}{l}\text { High } \\
(n=110)\end{array} \\
44(40.0 \%)\end{array}$} & \multirow{2}{*}{\begin{tabular}{|l|} 
p value \\
0.10 \\
\end{tabular}} \\
\hline \multirow{3}{*}{$\begin{array}{l}\text { Age } \\
\text { (years) }\end{array}$} & $11-12$ & & & & \\
\hline & 13-14 & $50(45.0 \%)$ & $43(38.7 \%)$ & $32(29.1 \%)$ & \\
\hline & $15-16$ & $29(26.1 \%)$ & $25(22.5 \%)$ & $34(30.9 \%)$ & \\
\hline \multirow[t]{2}{*}{ Gender } & Male & $6(5.4 \%)$ & $16(14.4 \%)$ & $47(42.7 \%)$ & \multirow[t]{2}{*}{$<.001$} \\
\hline & Female & $105(94.6 \%)$ & $95(85.6 \%)$ & $63(57.3 \%)$ & \\
\hline
\end{tabular}

Regarding nutritional pattern, different attitudes were observed in different SES. The incidence of taking vitamins and supplements was found to be more in respondents belonging to high SES than those from low SES. The results were found to be statistically significant in three SES $(p=0.022)$. The incidence of taking fourth meal in a day was lower in low SES than other socioeconomic groups $(p=0.018)$. But the results were opposite regarding the habit of taking breakfast $(p=0.114)$. Results were same in all socioeconomic groups as far as intake of water was concerned $(p=0.136)$ but these were statistically significant $(p=0.025)$ when intake of juices was considered. The incidence of eating food during school hours was more from home in respondents from high SES while more of respondents from low SES were eating from school cafeteria. The results were found to be statistically significant $(p=0.063)$. The frequency of taking sweets and deserts is more in respondents from low SES than those from high SES but the difference is not statistically significant $(p=0.765)$. Similarly the respondents from low SES take vegetables less frequently than those of middle and high SES. These results were found to be statistically significant $(p=0.016)$. On the contrary, the 
frequency of fast food intake was significantly higher in respondents from high SES than those from low SES. The results were found to be statistically significant $(p=<0.001)$, but the results were almost same for taking French fries and chips. The results were quite similar in case of intake of fish by different socioeconomic groups $(p=0.011)$. the incidence of taking milk and its products (yogurt, cheese) was also found to be higher in respondents from high SES and results were found to be statistically significant $(p=<0.001)$ (Table 2$)$

Table 2: dietary pattern of respondents according to SES

\begin{tabular}{|c|c|c|c|c|}
\hline Variables & $\begin{array}{l}\text { Low SES } \\
(n=111)\end{array}$ & $\begin{array}{l}\text { Middle SES } \\
(n=111)\end{array}$ & $\begin{array}{l}\text { High SES } \\
(n=110)\end{array}$ & p value \\
\hline Taking vitamins \& supplements & $26(23.4 \%)$ & $22(19.8 \%)$ & $39(35.5 \%)$ & 0.022 \\
\hline \multicolumn{5}{|l|}{ Total meals per day } \\
\hline $1-2$ meals & $27(24.3 \%)$ & $35(31.5 \%)$ & $28(25.5 \%)$ & \\
\hline 3 meals & $77(69.4 \%)$ & $55(49.5 \%)$ & $65(59.1 \%)$ & 0.018 \\
\hline Often a $4^{\text {th }}$ & $7(6.3 \%)$ & $21(18.9 \%)$ & $17(15.5 \%)$ & \\
\hline \multicolumn{5}{|l|}{ Take breakfast } \\
\hline Daily & $67(60.4 \%)$ & $64(57.7 \%)$ & $78(70.9 \%)$ & \\
\hline Sometimes & $26(23.4 \%)$ & $29(26.1 \%)$ & $16(14.5 \%)$ & 0.114 \\
\hline Rarely & $12(10.8 \%)$ & $13(11.7 \%)$ & $6(5.5 \%)$ & \\
\hline Not at all & $6(5.4 \%)$ & $5(4.5 \%)$ & $10(9.1 \%)$ & \\
\hline \multicolumn{5}{|l|}{ Glasses of water } \\
\hline $1-2$ per day & $18(16.2 \%)$ & $9(8.1 \%)$ & $13(11.8 \%)$ & 0.136 \\
\hline $3-4$ per day & $41(36.9 \%)$ & $45(40.5 \%)$ & $36(32.7 \%)$ & \\
\hline 5-6 per day & $29(26.1 \%)$ & $26(23.4 \%)$ & $29(26.4 \%)$ & \\
\hline $7-8$ per day & $8(7.2 \%)$ & $22(19.8 \%)$ & $18(16.4 \%)$ & \\
\hline$>8$ per day & $15(13.5 \%)$ & $9(8.1 \%)$ & $14(12.7 \%)$ & \\
\hline \multicolumn{5}{|l|}{ Fruit juices } \\
\hline Once a day & $32(28.8 \%)$ & $33(29.7 \%)$ & $35(31.8 \%)$ & 0.025 \\
\hline Once a week & $51(45.9 \%)$ & $38(34.2 \%)$ & $27(24.5 \%)$ & \\
\hline Twice a day & $8(7.2 \%)$ & $9(8.1 \%)$ & $9(8.2 \%)$ & \\
\hline Twice a week & $18(16.2 \%)$ & $2219.8 \%)$ & $25(22.7 \%)$ & \\
\hline \multicolumn{5}{|l|}{ Food during school hours } \\
\hline Lunch box & & & & 0.063 \\
\hline School cafeteria & $35(31.5 \%)$ & $40(36.0 \%)$ & $57(51.8 \%)$ & \\
\hline \multirow[t]{2}{*}{ Both } & $59(53.2 \%)$ & $55(49.5 \%)$ & $44(40.0 \%)$ & \\
\hline & $17(15.3 \%)$ & $16(14.5 \%)$ & $9(8.2 \%)$ & \\
\hline
\end{tabular}




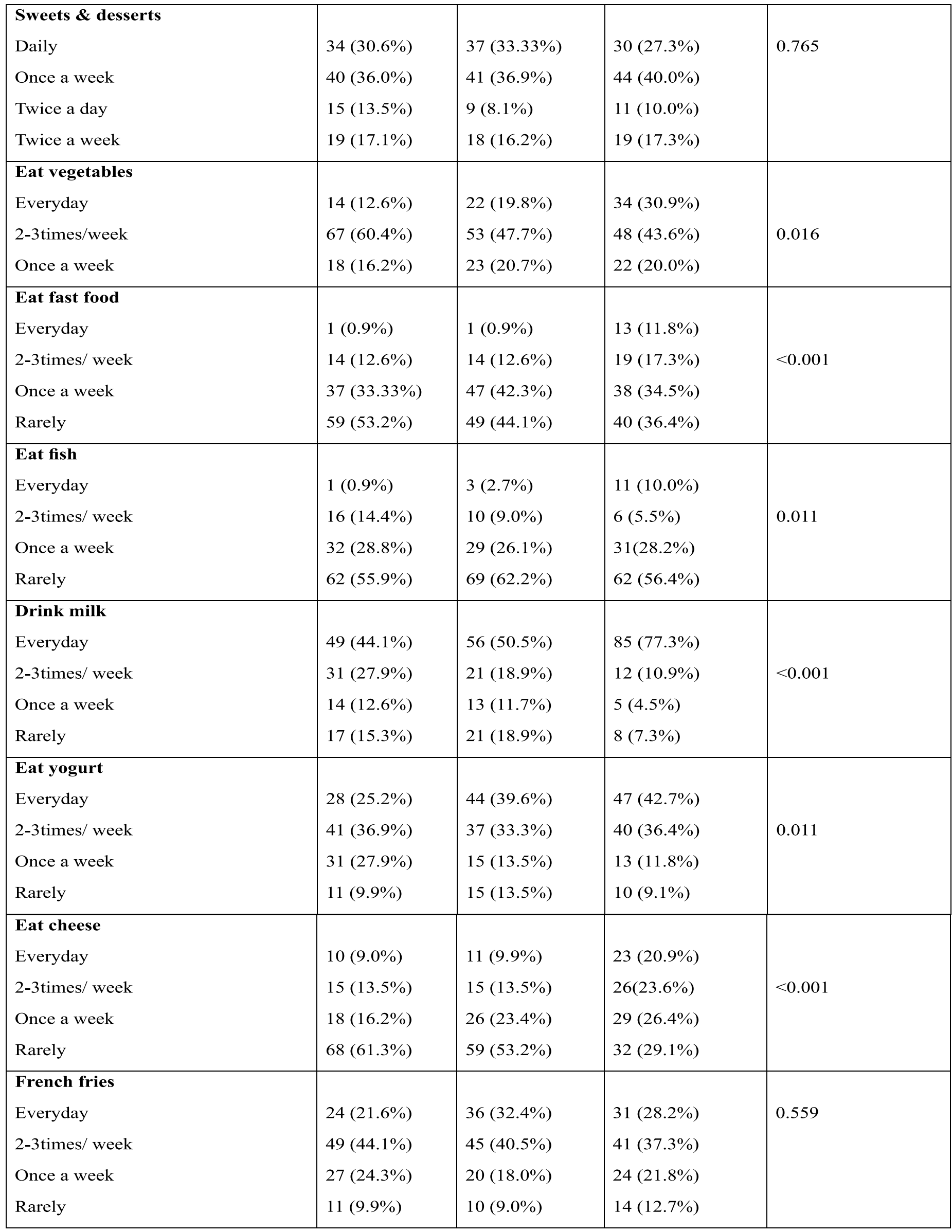


The results also showed that most of respondents from low SES were underweight with low BMI while incidence of obesity was more in respondents from higher SES. The results were found to be statistically significant $(p=0.025)$. (Chart 1$)$

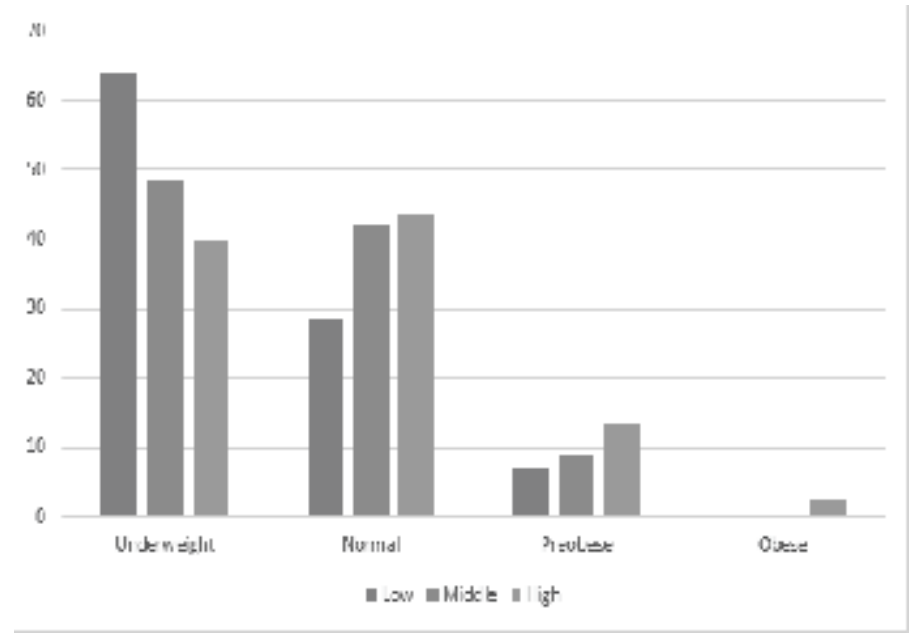

Figure 1: showing incidence of obesity in different socioeconomic groups.

Regarding Physical Activity and Life Style of respondents, most of them from all socioeconomic groups prefer to walk for short distance but ratio of those using mechanical ways of transport for short distance was more in respondents from high SES. The results were found to be statistically significant $(p$ value $=$ 0.006). The trend of using stairs instead of elevators was predominantly higher in low SES group. Similarly most of the respondents from low SES group have been restricted to use computer in comparison to those from high SES ( $p$-value $=0.040$ ). The trend of visiting outside places to eat out was found to be significantly high among respondents from high SES. When asked about their activities during leisure time, most of the respondents from low SES preferred indoor activities but outdoor sports were preferred by respondents from middle and high SES. The preference for sleeping was almost same in all groups. The results were found to be statistically significant $(p$-value $=0.007$ ).

The trend for exercise was slightly more in respondents from low SES but results were not statistically significant ( $p$ value $=0.285$ ). About quarter of respondents from each group did not exercise at all. (Table 3 )
Table 3: Physical Activity and Life Style of respondents according to SES groups

\begin{tabular}{|c|c|c|c|c|}
\hline Variables & Low SES & Middle SES & High SES & p value \\
\hline $\begin{array}{l}\text { Modes of transport for } \\
\text { short distance } \\
\text { Walk } \\
\text { Bicycle } \\
\text { Car }\end{array}$ & $\begin{array}{l}64(57.7 \%) \\
9(8.1 \%) \\
31(27.9 \%)\end{array}$ & $\begin{array}{l}74(66.7 \%) \\
9(8.1 \%) \\
23(20.7 \%)\end{array}$ & $\begin{array}{l}48(43.6 \%) \\
21(19.1 \%) \\
38(34.5 \%)\end{array}$ & 0.006 \\
\hline $\begin{array}{l}\text { Takes stairs instead of } \\
\text { elevator } \\
\text { Always } \\
\text { Often } \\
\text { Sometimes } \\
\text { Never }\end{array}$ & $\begin{array}{l}29(26.1 \%) \\
23(20.7 \%) \\
47(42.3 \%) \\
12(10.8 \%)\end{array}$ & $\begin{array}{l}37(33.3 \%) \\
24(21.6 \%) \\
33(29.7 \%) \\
17(15.3 \%)\end{array}$ & $\begin{array}{l}48(43.6 \%) \\
26(23.6 \%) \\
27(24.5 \%) \\
9(8.2 \%)\end{array}$ & 0.036 \\
\hline Limit time using computer & $81(73.0 \%)$ & $63(56.8 \%)$ & $70(63.6 \%)$ & 0.040 \\
\hline Visit places to eat out & $10(9.0 \%)$ & $22(19.8 \%)$ & $33(30.0 \%)$ & $<0.001$ \\
\hline $\begin{array}{l}\text { Activities during leisure } \\
\text { time } \\
\text { indoor } \\
\text { sleep } \\
\text { sports }\end{array}$ & $\begin{array}{l}33(29.7 \%) \\
21(18.9 \%) \\
37(33.3 \%)\end{array}$ & $\begin{array}{l}25(22.5 \%) \\
15(13.5 \%) \\
56(50.5 \%)\end{array}$ & $\begin{array}{l}19(17.3 \%) \\
22(20.0 \%) \\
58(52.7 \%)\end{array}$ & $\begin{array}{l}0.088 \\
0.396 \\
0.007\end{array}$ \\
\hline $\begin{array}{l}\text { Exercise } \\
\text { Daily } \\
\text { Weekly } \\
\text { Monthly } \\
\text { Not at all }\end{array}$ & $\begin{array}{l}44(39.6 \%) \\
22(19.8 \%) \\
15(13.5 \%) \\
30(27.0 \%)\end{array}$ & $\begin{array}{l}43(38.7 \%) \\
19(17.1 \%) \\
15(13.5 \%) \\
34(30.6 \%)\end{array}$ & $\begin{array}{l}39(35.5 \%) \\
33(30.0 \%) \\
16(14.5 \%) \\
22(20.0 \%)\end{array}$ & 0.285 \\
\hline
\end{tabular}

\section{Discussion}

This study is based on trends of malnourishment and physical inactivity in childhood and adolescence in different socioeconomic status. Several serious diseases have their roots in adolescence. Lack of awareness regarding balanced diet and optimal physical activity, increased trend of a particular kind of food, socioeconomic inequality and increasing incidence of metabolic and chronic diseases are the major reasons that make this issue complex and widespread with serious end results at individual and country level. This study correlates nutritional imbalance and physical activity of students with their socioeconomic status. Identification of diseases prevalent in particular SES is helpful in identifying the population at risk for that particular disease and to take specific measures of prevention, early diagnosis and prompt treatment. This also aids to ensure equal distribution of resources among the population and also to create awareness related to healthy dietary practice, optimum physical activity and healthy lifestyle.

We used income and family size as main indicator of SES. Distribution of age in different SES is nearly similar. Intake of different types of foods are different in respondents from different socioeconomic groups depending on availability and level of awareness.

$\mathrm{BMI}$ shows a classic trend. Maximum undernourished is found in low SES, more normal category is found in both 
middle and high SES while obese are found in high SES comparatively. The trend is found consistent with the previous research studies 19, 20, 21. These results also supported by Youfa in 200122.

Respondents were also observed for their physical activity. Physical activity is important as to prevent many chronic diseases e.g. diabetes mellitus. Physical activity of the respondents was assessed by by their life style and trend for exercise. Major difference was found in life style. Exercise trend was found to be nearly similar in all three SES. The same trend is found in previous studies23.

Our study has some limitations. This study is on the behavior regarding nutrition and physical activity of only school going children and not every children of every age in a community. However the study is not gender biased. Details of diseases and their treatment is not been discussed. This research is based on prevalence of malnourishment and physical inactivity in children and adolescent. Further research is needed to investigate the effects of malnourishment and physical inactivity afterwards in the adult life. Beside SES, other causes of malnourishment should also be investigated.

\section{Conclusion}

The whole data summarizes that respondents of low SES tend to be more undernourished and are involved in inexpensive kinds of physical activities like walk, house cleaning etc. this leads to anemia related symptoms including dizziness, tired for no reason, decrease cognition and self-esteem. On the other hand, middle and high SES show almost similar features. They are more prone to be obese and have more trend of fast food because of more availability of resources. Most of respondents have optimum physical activity usually in form of sports. This deduces that availability of balanced diet to each socioeconomic class is necessary to prevent incidence of chronic diseases. For this, complete assurance of socioeconomic equality should be encouraged so that equal distribution of resources along with awareness programs promote health of the individual and produce a healthy, energetic community that will contribute to the progress and prosperity of country in long term.

\section{References}

1. LeFevre ML. U.S. Preventive Services Task Force, Behavioral counseling to promote a healthful diet and physical activity for cardiovascular disease prevention in adults with cardiovascular risk factors: U.S. Preventive Services Task Force Recommendation Statement. Ann Intern Med. 2014 Oct 21; 161(8):587-93.

2. Andrew L. Kau, Philip P. Ahern, Nicholas W. Griffin, Andrew L. Goodman \& Jeffrey I. Gordon. Human nutrition, the gut microbiome and the immune system. doi:10.1038/nature 10213.

3. Raubenheimer D, Jones S.A. Nutritional imbalance in an extreme generalist omnivore: tolerance and recovery through complementary food selection. Animal Behaviour.Volume 71, Issue 6, June 2006: Pages 1253-1262

4. Michael O. Leavitt. 2008 Physical Activity Guidelines for Americans, Department of Health and Human Services, USA. Available from http://www.nhlbi.nih.gov/health

5. Hartley L, Igbinedion E, Holmes J, Flowers N, Thorogood $M$,Clarke A, Stranges $S$, et al. Increased consumption of fruit and vegetables for the primary prevention of cardiovascular diseases. Cochrane Database of Systematic Reviews 2013, Issue 6. Art. No.: CD009874. DOI: 10.1002/14651858.CD009874.pub2.

6. Developing children's social and emotional skills. Available from https://www.kidsmatter .edu.au/sites/default/files/public/FrameworkBo ok Component2.pdf

7. Carolina Carvalho de Oliveira, Telma Maria Braga Costa, Maria Fernanda Laus. Eating habits and inappropriate behavior for weight control in adolescents enrolled in gyms. Adolesc. Saude, Rio de Janeiro; v. 9, n. 3: p. 47-55, jul/set 2012.

8. Jennifer S, Fisher J O, and Birch L L. Parental Influence on Eating Behavior. J Law Med Ethics. 2007; 35(1): 22-34.

9. Khan M A and Ihsan Ullah. Food and nutrition situation in Pakistan, progressive farming; Vol.4, No5, 1984

10. Why we eat what we eat: social and economic determinants of food choice, European Food Information Council, 2004. Available from http://www.eufic.org/article/en/health-andlifestyle/food-choice/artid/social-economicdeterminants-food-choice/

11. Boskey, E. Socioeconomic status. 2017. Retrieved from https://www.verywell .com/socioeconomic-status-ses-3132909

12. United Nations Convention on the Rights of the Child, 1989, UNICEF.UK 30A. Great Sutton Street. London EC1VODU.

13. Crawford, B. What is nutritional imbalance and what forms are there?. 2011; Retrieved from http://www.livestrong.com/article/547230

14. Caspersen, C. J., Powell, K. E., \& Christenson, G. M. Physical activity, exercise, and physical fitness: definitions and distinctions for healthrelated research, 1985. Public Health Rep. 1985 Mar-Apr; 100(2): 126-131.

15. Pakistan is world's sixth most populous country, 2013. Pakistan Today

16. Poverty in Pakistan, https://en.wikipedia.org /wiki/Poverty_in_Pakistan

17. Body Mass Index (BMI) Calculator, http://www.scientificpsychic.com/health/BodyMass-Index-BMI.html

18. MET Calculator,http://lamb.cc/calories-burned- 
calculator/

19. Parsons TJ, power C, Logan S, Summerbell CD. Childhood predictors of adult obesity: a systematic review. Int J Obes Relat Metab Disord, 1999,23(suppl.8):S1-107

20. Sobal J, Stunkard AJ. Socioeconomic status and obesity: a review of literature. Psychol Bull 1989;105:260-75.

21. Must A, Dallal GE, Dietz WH. Reference data for obesity: 85th and 95th percentile of body mass index and triceps skin fold thickness. Am J Clin Nut 1991;53:839-46

22. W.Youfa. Cross-national comparison of childhood obesity: the epidemic and the relationship between obesity and socioeconomic status, Int J Epidemiol (2001); 30 (5): 1129-1136

23. McMurray RG, Harrell JS, Deng S, Bradley CB, Cox LM, Bangdiwala Sl.. The influence of physical activity, SES and ethnicity on the weight status of adolescents. Obes Res. 2000 Mar;8(2):130-9 